\title{
Erratum to: Laser-Aided Direct Writing of Nickel- Based Single-Crystal Super Alloy (N5)
}

YICHEN WANG, JEONGYONG CHOI, and JYOTI MAZUMDER

DOI: $10.1007 / \mathrm{s} 11661-017-4132-8$

(C) The Minerals, Metals \& Materials Society and ASM International 2017

Erratum to: METALLURGICAL AND MATERIALS

TRANSACTIONS A, VOLUME 47A,

DECEMBER 2016, pp. 5685-5690

DOI 10.1007/s11661-016-3755-5

IN the original article Jeongyong Choi's given name is misspelled. It is corrected as shown in this erratum.

YICHEN WANG, Graduate Student, is with the Department of Materials Science and Engineering, University of Michigan, Ann Arbor, MI 48109-2125. JEONGYONG CHOI, Graduate Student, is with the Department of Mechanical Engineering, University of Michigan. JYOTI MAZUMDER, Robert $\mathrm{H}$ Lurie Professor of Engineering, is with the Department of Materials Science and Engineering, University of Michigan, and also with the Department of Mechanical Engineering, University of Michigan. Contact e-mail: mazumder@umich.edu

The online version of the original article can be found under doi: 10.1007/s11661-016-3755-5.

Article published online May 15, 2017 